\title{
Correction to: Curcumin protects dopaminergic neurons against inflammation-mediated damage and improves motor dysfunction inducedby single intranigral lipopolysaccharide injection
}

\author{
Neha Sharma ${ }^{1} \cdot$ Sheetal Sharma ${ }^{1} \cdot$ Bimla Nehru ${ }^{1}$
}

Published online: 16 November 2021

๑) Springer Nature Switzerland AG 2021

\section{Correction to: Inflammopharmacology (2017) 25:351-368 https://doi.org/10.1007/s10787-017-0346-z}

After publication of this original article, few errors were reported in Figures 2(A), 4(A) and 6(A). In Fig. 2(A) the sections were different, although a repeating pattern was observed in representative IHC images of Sham and Curcumin group. To provide better clarity we have provided another representative image from Curcumin group. Fig. 4(A) IHC image from LPS+Curcumin group was accidently misused in LPS group. We have replaced all the images of Fig. 4A in order to keep the scale bar constant and provide better differentiation among the groups.

This will not affect the graphical representation of Iba-1 and TH positive cell count. During analysis several IHC stained sections from different animals were considered for cell counting using image $\mathbf{J}$ software and mean graph was plotted. (Mentioned in methodology section 2.12).

The original article can be found online at https://doi.org/10.1007/ s10787-017-0346-z.

Bimla Nehru

bnehru@pu.ac.in

Neha Sharma

jaitly_neha@rediffmail.com

1 Department of Biophysics, Panjab University,

Chandigarh 160014, India 
Corrected Figs. 2 and 4 are provided below:

(A)
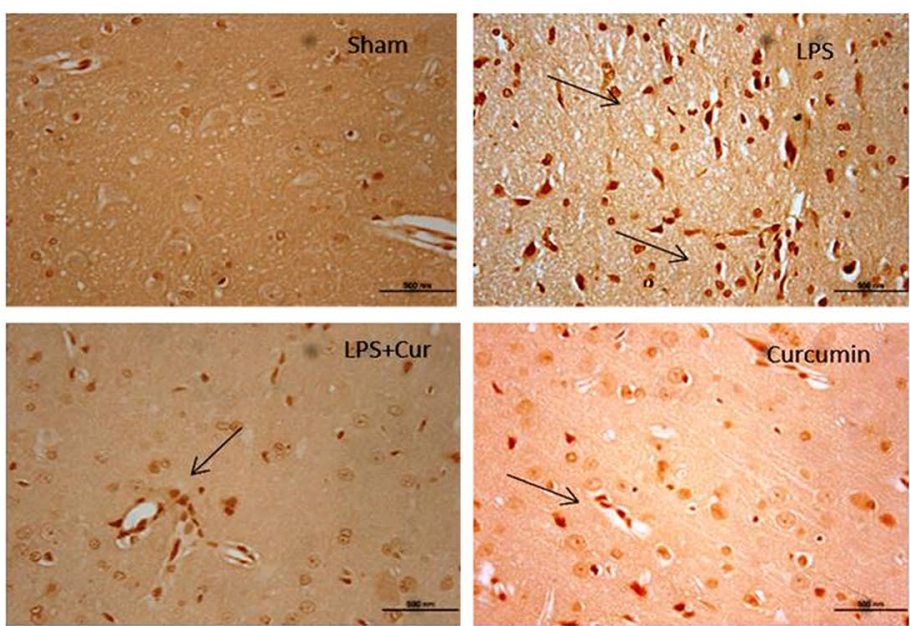

(B)

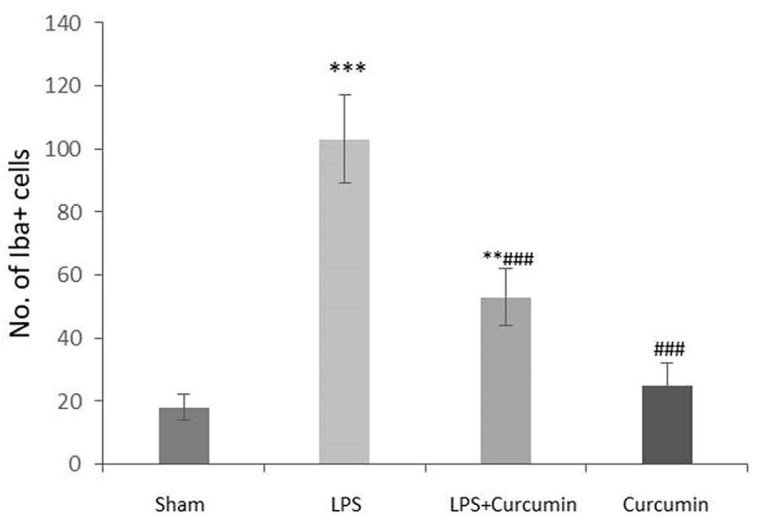

Fig. 2 Effect of curcumin on LPS induced microglial activation as depicted by IHC analysis. Immunohistochemistry for Iba-1. Representative slides showing coronal section of the brain at $(40 \times$ magnification) indicating intensely stained microglia present in large numbers seen in dark brown color by DAB (marked by arrows) which is characteristic of inflammation were seen in LPS group. However, marked reduction in the number of activated microglia can be seen in LPS + Curcumin group. The data are reported as the mean \pm SD $(n=6)$. Statistical significance $* * * p \leq 0.001, * * p \leq 0.01, * p \leq 0.05$ significant when compared with sham. \#\# $p \leq 0.001,{ }^{\# \#} p \leq 0.01$, ${ }^{\#} p \leq 0.05$ significant when compared with LPS treated group
(A)
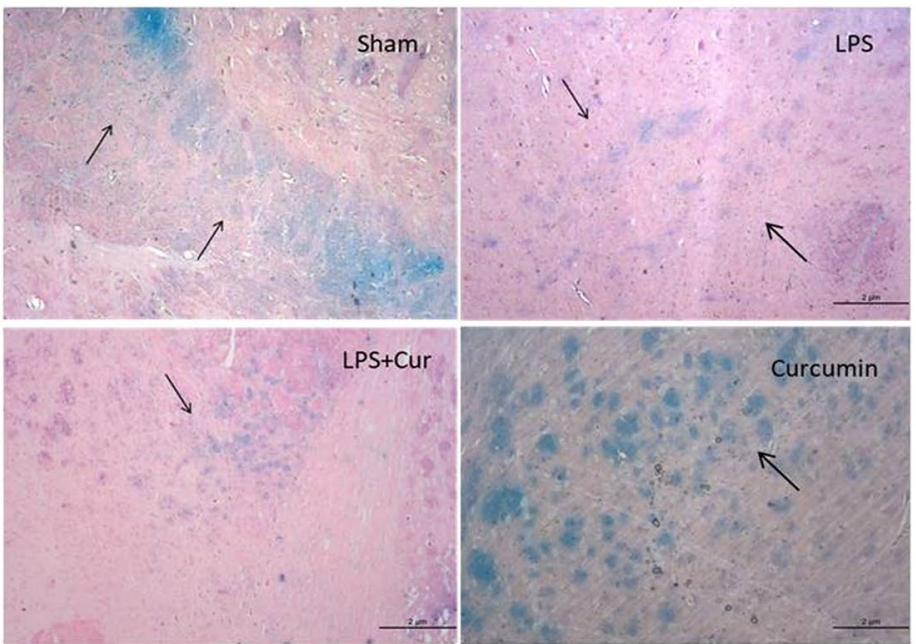

(B)

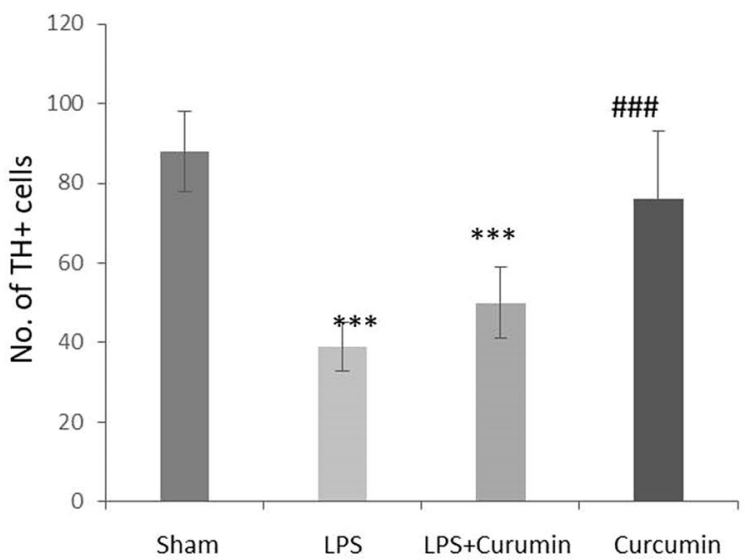

Fig. 4 Effect of curcumin on LPS induced loss of tyrosine hydroxylase (TH) marker for dopaminergic cells as depicted by IHC analysis. Immunohistochemistry for $\mathrm{TH}$. Representative slides showing coronal section of the brain at (40× magnification) indicating $\mathrm{TH}+$ cells in all treatment groups. The data are reported as the mean \pm SD $(n=6)$. Statistical significance $* * * p \leq 0.001, * * p \leq 0.01, * p \leq 0.05$ significant when compared with sham. ${ }^{\# \# \#} p \leq 0.001$, \# $p \leq 0.01$, ${ }^{\#} p \leq 0.05$ significant when compared with LPS treated group 
The authors regret that the Fig. 6(A) containing representative PCR bands is not of sufficient quality and should be replaced. During the final steps of figure preparation an improper insertion of bands took place which has led to this error. This probably resulted from low resolution of images and large no. of groups run simultaneously for dose standardization. In order to meet the standards of the journal and accuracy we wish to perform corrigendum of Fig. 6(A) (NFkb and IL-1 $\beta$ ). This would not affect the graphical representation of the bands and the scientific merit. Corrected Fig. 6 is provided below.
Fig. 6 Effect of curcumin on LPS induced alterations on mRNA expression of transcription factor NFkB, pro-inflammatory cytokines (TNF- $\alpha$, IL- $1 \beta$, IL- $1 \alpha)$ and iNOS. $\beta$-actin expression was used as a control. The histograms shows quantitative densitometric analysis normalized to that of control $\beta$-actin. The data are reported as the mean $\pm \mathrm{SD}$ $(n=6)$. Statistical significance $* * * p \leq 0.001, * * p \leq 0.01$, $* p \leq 0.05$ significant when compared with sham. ${ }^{\# \#} p \leq 0.001$, ${ }^{\# \#} p \leq 0.01,{ }^{\#} p \leq 0.05$ significant when compared with LPS treated group
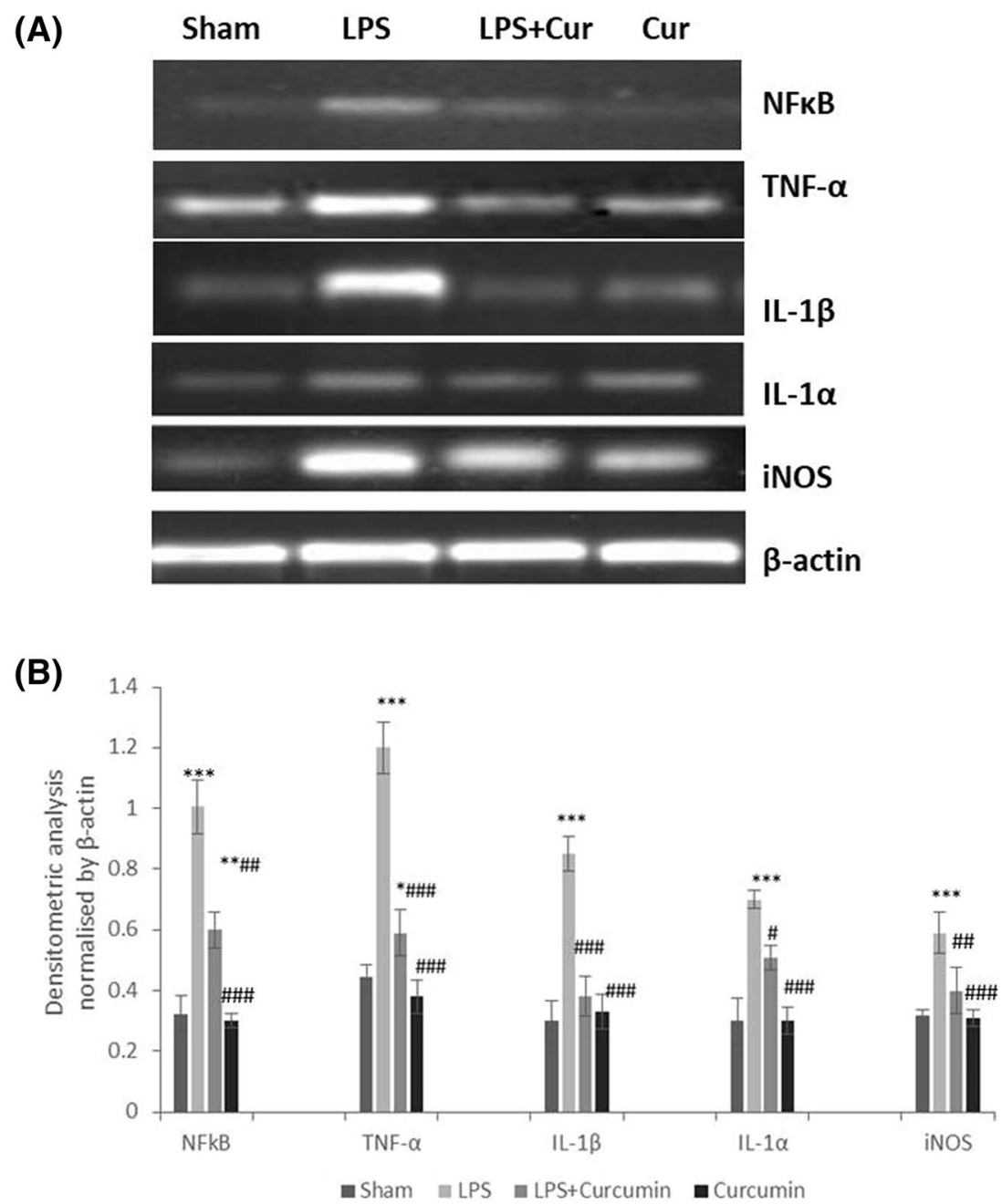

The authors would like to apologize for any inconvenience caused to the readers.
Publisher's Note Springer Nature remains neutral with regard to jurisdictional claims in published maps and institutional affiliations. 